\title{
Efficiency of organic ligands in adsorptive dissolution and photoreductive dissolution of hematite
}

\author{
P. Mukherjee ${ }^{1}$ Y. Gao ${ }^{1}$
}

Received: 10 October 2015/Revised: 7 February 2016/Accepted: 28 February 2016/Published online: 17 March 2016

(C) Islamic Azad University (IAU) 2016

\begin{abstract}
Organic ligands, especially oxalate, play an important role in iron dissolution from iron-containing minerals. To study the effects of organic acid ligands on the dissolution of iron-containing minerals, the dissolution kinetics of hematite in the presence of oxalate, acetate, and formate were studied under ultraviolet radiation with varying ligand concentrations $(10-3 \mathrm{mM})$. The results indicate that for adsorption dissolution, oxalate is the dominating ligand for producing soluble iron (III) from hematite; for photoreductive dissolution under ultraviolet radiation and in oxic conditions, the production of iron (II) is highly proportional to the concentrations of oxalate, whereas the effects of varying concentrations of formate and acetate are not significant. At low oxalate concentrations $(10-500 \mu \mathrm{M})$, the photoreductive dissolution of iron (II) is substantially low, while at high oxalate concentrations $(3 \mathrm{mM})$, oxalate is equally effective as formate and acetate for producing photoreduced iron (II) from hematite. Combining with field data from other works, it is likely that the ratios of oxalate to total iron need to be higher than a threshold range of $\sim 1.2-5.5$ in order for oxalate to effectively produce photoreduced iron (II) from hematite. This study demonstrates that the iron (II) yield from photoreduction of hematite is significantly lower when the hematite surface is pre-coated with organic ligands versus when it is exposed to ultraviolet radiation instantaneously.
\end{abstract}

Keywords Dissolution - Hematite - Organic ligands . Photoreduction

Y. Gao

yuangaoh@andromeda.rutgers.edu

1 Department of Earth and Environmental Sciences, Rutgers University, Newark, NJ 07102, USA

\section{Introduction}

Iron $(\mathrm{Fe})$ is an essential nutrient for phytoplankton growth in the oceans' high nitrate and low chlorophyll (HNLC) regions (Martin et al. 1990; Sunda and Huntsman 1997; Martin and Fitzwater 1988), affecting the carbon cycle (Martin 1990). Most of the dissolved $\mathrm{Fe}$ in the ocean, operationally defined as those that pass through a filter of $0.45 \mu \mathrm{m}$ pore size (Gledhill and van den Berg 1995 ), exists as hydroxides or in strongly chelated complexes with naturally occurring organic ligands (Sung and Morgan 1980; Rue and Bruland 1995; van den Berg 1995; Johnson et al. 1997; Wu et al. 2001; Liu and Millero 2002). However, iron remains insoluble under oxic conditions with a $\mathrm{pH}$ above 4 (Jickells et al. 2005), thereby being unavailable for the phytoplanktons to consume. Phytoplanktons could easily uptake Fe in its reduced form (Shaked et al. 2005), $\mathrm{Fe}(\mathrm{II})$; however, some evidences claim that inorganic soluble Fe(III), organic ligand-Fe(III) complexes, and some colloidal form of $\mathrm{Fe}$ (III) could also be consumed by microorganisms, such as red tide microalgae (Naito et al. 2005). It is reported that a potential source of bioavailable iron is photoreductive dissolution of particulate iron oxides (Finden et al. 1984). Both Fe(II) and Fe(III) could be produced on aerosol particles in the atmosphere, affected by the presence of peroxide radicals (Zuo and Hoigne 1992), organic ligands (Siefert et al. 1994), and solar radiation (Zhu et al. 1993, 1997; Paris et al. 2011). Consequently, understanding Fe speciation and solubility in aerosols is crucial for estimating the atmospheric deposition of bioavailable Fe to the ocean.

The oxidizing atmosphere in general favors the dissolved $\mathrm{Fe}(\mathrm{III})$ over $\mathrm{Fe}(\mathrm{II})$ in $\mathrm{Fe}$-containing minerals, such as hematite, lepidocrocite, goethite, and several organic ligands play crucial roles in $\mathrm{Fe}$ dissolution, specially oxalate, 
through the complex formation with the $\mathrm{Fe}(\mathrm{III})$ and adsorption dissolution mechanism (Banwart et al. 1989; Sulzberger et al. 1989; Siffert and Sulzberger 1991; Xu and Gao 2008; Paris et al. 2011). Under the exposure to sunlight, the $\mathrm{Fe}(\mathrm{III})$-ligand complex absorbs energy from ultraviolet (UV) radiation; and the ligand acts as a bridge and supplies electrons to the $\mathrm{Fe}$ (III) metal center, resulting in the formation of Fe(II) (Zhu et al. 1997; Siffert and Sulzberger 1991; Chen and Grassian 2013). Acetate and formate are also common organic ligands in the ambient air (Kawamura and Kaplan 1983; Kawamura and Kouichi 1993a, b; Li and Winchester 1993; Chebbi and Carlier 1996; Kawamura and Sakaguchi 1999; Johansen et al. 2000; Paris and Desboeufs 2013). However, the ambient levels of these organic acidic species vary widely throughout the global atmosphere. For example, the concentrations of oxalate were observed to be 8.7-667 $\mathrm{ng} \mathrm{m}^{-3}$ in the North Pacific (Johansen et al. 2000), $<12.4-100.8 \mathrm{ng} \mathrm{m}^{-3}$ in the Atlantic (Kawamura and Kouichi 1993b), \{below detection limit\}-48.4 $\mathrm{ng} \mathrm{m}^{-3}$ in Ny-Alesund, Svalbard, in the Arctic (Keiichiro et al. 2002) in the marine regions. In the urban regions, the concentration of oxalate was relatively high, for example, $2.1-9.7 \mathrm{nmol} \mathrm{m}^{-3}$ (which is equivalent to $184.8-853.6 \mathrm{ng} \mathrm{m}^{-3}$ ) at Newark, $\mathrm{NJ}$ (Xia and Gao 2010), 90-780 $\mathrm{ng} \mathrm{m}^{-3}$ in West Los Angeles (Kawamura and Kaplan 1987), and 40-730 $\mathrm{ng} \mathrm{m}^{-3}$ in Tokyo, Japan (Kawamura and Ikushima 1993).

Among these three ligands mentioned above, oxalate is the most abundant one in atmospheric aerosols (Chen and Grassian 2013; Turekian et al. 2003; Krieger et al. 2006) and it is also believed to be the most effective one affecting $\mathrm{Fe}$ dissolution from $\mathrm{Fe}$ minerals through the formation of stable bi-dentate chelates with the Fe metal centers (Sulzberger et al. 1989; Siffert and Sulzberger 1991; Paris and Desboeufs 2013). In previous experimental studies (Banwart et al. 1989; Sulzberger et al. 1989; Xu and Gao 2008), the concentrations of oxalate were mainly held at the levels of 50 to 600 times higher than the atmospheric concentrations of oxalate found in rainwater (Paris and Desboeufs 2013). However, in the atmosphere where the concentrations of oxalate are low while both the solar radiation and adequate oxygen are prevalent, the interactions of oxalate with $\mathrm{Fe}$ minerals are complicated. For instance, under adequate $\mathrm{O}_{2}$ exposure and solar radiation, the $\mathrm{Fe}(\mathrm{II})$ production from reducing $\mathrm{Fe}(\mathrm{III})$ could be substantially altered by $\mathrm{H}_{2} \mathrm{O}_{2}$ produced during reactions, resulting in less yield for Fe(II) (Zuo and Hoigne 1992; Siefert et al. 1994). In addition, the photolysis of oxalate under UV radiation could also produce $\mathrm{H}_{2} \mathrm{O}_{2}$ that limits the $\mathrm{Fe}$ (II) formation (Zuo and Hoigne 1992). Therefore, the concentrations of oxalate at different levels could significantly affect the $\mathrm{Fe}$ (II) production rate and then $\mathrm{Fe}$ speciation that still remains untested. Furthermore, despite being present in the atmosphere at levels comparable to oxalate, acetate and formate have not been studied extensively for $\mathrm{Fe}(\mathrm{II})$ production in Fe minerals. On the other hand, the complexation of $\mathrm{Fe}(\mathrm{III})$ with organic ligands was found stable, but these complexes could undergo photoreductive dissolution, resulting in the formation of $\mathrm{Fe}(\mathrm{II})$. It is still in question whether the incident solar radiation could produce Fe(II) from the organic ligand-Fe(III) complexes in the atmosphere. Fluoride could also form complex with Fe(III) (Dodgen and Rollefson 1949; Soli and Byrne 1996; Wang and Reardon 2001; Dey et al. 2004) but the effect of fluoride in promoting dissolution of $\mathrm{Fe}(\mathrm{III})$ from $\mathrm{Fe}$ minerals is yet to be explored.

To investigate the effects of $\mathrm{Fe}$ dissolution from $\mathrm{Fe}$ containing minerals, laboratory experiments involving hematite and organic ligands (oxalate, acetate, and formate) were carried out at Rutgers University over an approximate 6-month period from November 2014 to April 2015. The specific objective were to investigate: (1) the effects of these ligands at different concentrations; (2) the relative efficiency of these ligands on the photoreductive dissolution and adsorptive dissolution of $\mathrm{Fe}(\mathrm{III})$, along with a comparison to fluoride; and (3) the effect of prior complexation with ligands on the generation of $\mathrm{Fe}(\mathrm{II})$ via photoreduction. The results from this study will shed further light on current understanding of iron speciation and solubility in ambient aerosols and advance our knowledge of the effect of organic ligands, particularly oxalate, on iron dissolution. The threshold ratios of oxalate to total $\mathrm{Fe}$ as an indicator of oxalate-promoted $\mathrm{Fe}(\mathrm{II})$ dissolution derived from this study could be used in future model studies.

\section{Materials and methods}

\section{Preparation}

All materials used in this experiment were either pure or analytical grade. Standard pure hematite $\left(\mathrm{a}-\mathrm{Fe}_{2} \mathrm{O}_{3}\right)$ was purchased (Atlantic Equipment Engineers, Bergenfield, NJ) and used in this study, which has the molecular weight 159.69 and $99.9 \%$ purity and specific surface area of $2.7 \mathrm{~m}^{2} \mathrm{~g}^{-1}$ for particle sizes of $1-5 \mu \mathrm{M}$. All solutions were prepared using $18.2 \mathrm{M} \Omega \mathrm{cm}$ Milli-Q water (Millipore, Bedford, MA, USA). Polyethylene 50-ml test tubes were pre-cleaned thoroughly before use. The UVLMS-38 EL series $3 \mathrm{UV}$ (capacity $8 \mathrm{~W}$ ) lamp was used as the source of UV radiation. The stock solutions for $\mathrm{Fe}(\mathrm{II})$ and $\mathrm{Fe}$ (III) were prepared by dissolving ammonium iron(II) sulfate 6-hydrate and ferric chloride, respectively. The stock solutions of the organic ligands were prepared from their sodium salts. All stock solutions were kept at $4{ }^{\circ} \mathrm{C}$ temperature in the refrigerator and the working standards were prepared before each analysis. 


\section{Experimental procedures}

Four experiments were carried out: The first experiment was for studying the effects of varying oxalate concentrations (ranging from $10 \mu \mathrm{M}$ to $3 \mathrm{mM}$ ) in photoreductive dissolution of $\mathrm{Fe}(\mathrm{II})$. The second experiment was conducted to compare the dissolution of $\mathrm{Fe}(\mathrm{II})$ via photoreduction in the presence of three different ligands (oxalate, acetate, and formate). Third experiment was to study the photoreductive dissolution of $\mathrm{Fe}$ (II) from hematite under two conditions: instantaneous irradiation of the Fe(III)-ligand complexes and pre-coated Fe(III)-ligand complexes. The fourth experiment focused on investigating the role of varying ligands (oxalate, acetate, formate, and an inorganic ligand fluoride) on adsorptive dissolution of $\mathrm{Fe}(\mathrm{III})$. All these experiments were conducted using hematite as the reference material for iron and were repeated 2-3 times. The figures display the means and the ranges of the repeated set of experiments. Tables 1 and 2 show the Pearson correlation coefficients of the replicate sets of experiments and the ranges of the concentrations at equilibrium, where the ranges have been calculated combining the values from all the repeated sets of experiments. The detailed procedures are outlined below.

\section{Photoreductive production of $\mathrm{Fe}(\mathrm{II})$ from $\mathrm{Fe}(I I I)-$ ligand complex}

The dissolution experiment was conducted by placing $10 \mathrm{mg}$ of hematite in three series of 50-ml polyethylene test tubes containing oxalate, formate, and acetate solutions separately at four different concentrations $(10,50,500$, $3 \mathrm{mM}$ ). The mixtures were left for $24 \mathrm{~h}$ to attain the adsorption equilibrium ( $\mathrm{Xu}$ and Gao 2008). The mixtures were then placed in an overhead rotator for $12 \mathrm{~h}$ followed by centrifugation for $10 \mathrm{~min}$ at a relative centrifugal force of $3000 \times g$. The supernatants from each mixture were collected and placed under UV light source $(254 \mathrm{~nm}$ wavelength) for $24 \mathrm{~h}$. The $\mathrm{pH}$ of each solution was adjusted at 3.5 by adding $0.1 \mathrm{~N} \mathrm{HCl}$ solution, because the Fe becomes highly mobilized $\sim$ below $3.6 \mathrm{pH}$ from dust samples (Mackie et al. 2005). Periodic measurements (0.5, $1,1.5,2,2.5,3,4,5,12,18$, and $24 \mathrm{~h}$ ) of $\mathrm{Fe}$ (II) were taken from each solution after filtering the aliquots through a $0.45-\mu \mathrm{m}$ pore size PTFE filter.

\section{Instantaneous irradiation on photoreductive production of $\mathrm{Fe}(\mathrm{II})$ from $\mathrm{Fe}(\mathrm{III})$-ligand complex}

A comparative study was performed to investigate the effect of instantaneous irradiation on nascent $\mathrm{Fe}(\mathrm{III})$-ligand complex on the photoreductive dissolution of $\mathrm{Fe}(\mathrm{II})$. The aim of this study was to compare the efficiency of the $\mathrm{Fe}(\mathrm{III})-$ ligand complexes formed from pre-coated hematite versus the in situ produced nascent Fe(III)-ligand complexes in the photoreductive generation of $\mathrm{Fe}$ (II). To accomplish this objective, three series of 50-ml test tubes were prepared by placing $10 \mathrm{mg}$ of hematite in each in the presence of three organic ligands (oxalate, acetate, and formate) at two concentration levels $(50 \mu \mathrm{M}$ and $3 \mathrm{mM})$. The test tubes were then placed immediately under UV light $(254 \mathrm{~nm})$ for $24 \mathrm{~h}$. The sample aliquots were withdrawn periodically ( $\sim 1$-h interval) for $24 \mathrm{~h}$ of irradiation span using a $10-\mathrm{ml}$ syringe with $0.45-\mu \mathrm{m}$ PTFE filter to measure the concentrations of dissolved $\mathrm{Fe}(\mathrm{II})$. In contrast with 2.2.1., in this step, the Fe(III)-ligand complexes were irradiated instantaneously.

Formation of $\mathrm{Fe}(I I I)$ at varying concentrations of organic and inorganic ligands

Suspensions of $10 \mathrm{mg}$ hematite were prepared in four series of solutions containing oxalate, acetate, formate, and fluoride at two concentration ranges $(50 \mu \mathrm{M}$ and $3 \mathrm{mM})$ and were left for $24 \mathrm{~h}$ to attain the equilibrium. After then, the solutions were placed in an overhead rotator for $32 \mathrm{~h}$,
Table 1 The Pearson correlation coefficients between the data for the repeated experiments. When an experiment is repeated thrice, the average of the three intercorrelations among the three sets of data is presented

\begin{tabular}{lllll}
\hline & Oxalate & Acetate & Formate & Fluoride \\
\hline \multicolumn{2}{l}{ Photoreductive dissolution of Fe(II) (Fig. 2) } & & & \\
$10 \mu \mathrm{M}$ & 0.66 & 0.74 & 0.73 & N/A \\
$50 \mu \mathrm{M}$ & 0.56 & 0.59 & 0.65 & N/A \\
$500 \mu \mathrm{M}$ & 0.61 & 0.61 & 0.53 & N/A \\
$3 \mathrm{mM}$ & 0.90 & 0.95 & 0.89 & N/A \\
Photoreductive dissolution of Fe(II) after instantaneous UV irradiation (Fig. 3) & \\
$50 \mu \mathrm{M}$ & 0.54 & 0.50 & 0.53 & N/A \\
$3 \mathrm{mM}$ & 0.46 & 0.89 & 0.93 & N/A \\
Adsorption dissolution & of Fe(III) (Fig. 4) & & \\
$50 \mu \mathrm{M}$ & 0.95 & 0.70 & 0.76 & 0.61 \\
$3 \mathrm{mM}$ & 0.92 & 0.85 & 0.59 & 0.47 \\
\hline
\end{tabular}


Table 2 Range of dissolved Fe concentrations $(\mu \mathrm{M})$ after reaching equilibrium

\begin{tabular}{|c|c|c|c|c|}
\hline & Oxalate & Acetate & Formate & Fluoride \\
\hline \multicolumn{5}{|c|}{ Photoreductive dissolution of Fe(II) (Fig. 2) } \\
\hline $10 \mu \mathrm{M}$ & $0.04-0.28$ & $0.28-0.98$ & $0.72-1.08$ & N/A \\
\hline $50 \mu \mathrm{M}$ & $0.10-0.29$ & $0.35-1.05$ & $0.70-1.23$ & N/A \\
\hline $500 \mu \mathrm{M}$ & $0.34-1.27$ & $0.51-1.18$ & $0.74-1.06$ & N/A \\
\hline $3 \mathrm{mM}$ & $1.34-2.6$ & $0.96-1.38$ & $1.5-2.52$ & N/A \\
\hline \multicolumn{5}{|c|}{ Photoreductive dissolution of $\mathrm{Fe}(\mathrm{II})$ after instantaneous UV irradiation (Fig. 3) } \\
\hline $50 \mu \mathrm{M}$ & $2.32-3.71$ & $2.62-3.47$ & $4.62-5.95$ & N/A \\
\hline $3 \mathrm{mM}$ & $5.26-9.95$ & $7.34-7.97$ & $7.86-9.08$ & N/A \\
\hline \multicolumn{5}{|c|}{ Adsorption dissolution of $\mathrm{Fe}$ (III) (Fig. 4) } \\
\hline $50 \mu \mathrm{M}$ & $8.9-12.3$ & $5.32-7.89$ & $6.97-9.36$ & $5.14-5.87$ \\
\hline $3 \mathrm{mM}$ & $12.3-14.9$ & $7.89-8.99$ & $8.9-11.0$ & $5.7-6.6$ \\
\hline
\end{tabular}

while aliquots were withdrawn periodically $(\sim 1$-h interval) followed by $10 \mathrm{~min}$ of centrifugation at $3000 \mathrm{rcf}$ to measure the concentration of soluble Fe(III) with time.

\section{Measurement of soluble $\mathrm{Fe}(\mathrm{II})$ and $\mathrm{Fe}(\mathrm{III})$}

The measurements of $\mathrm{Fe}(\mathrm{II})$ and $\mathrm{Fe}(\mathrm{III})$ concentrations were taken using Shimadzu UV-Vis 1700 spectrophotometer. The original ferrozine method (Stookey 1970; Voelker and Sulzberger 1996; Viollier et al. 2000) was followed with minor modification (Voelker and Sulzberger 1996) and background experiment to assess the interference of Fe(III) in ferrozine-Fe(II) complex formation. In the presence of both $\mathrm{Fe}$ (II) and $\mathrm{Fe}(\mathrm{III})$ in the solution, $\mathrm{Fe}$ (III) could form complex with ferrozine, thereby interfering with the $\mathrm{Fe}$ (II)-ferrozine complex coloration (Viollier et al. 2000). Therefore, the following equation was used to calculate $\mathrm{Fe}$ (II) and $\mathrm{Fe}$ (III) concentrations to eliminate the Fe(III) interference (Viollier et al. 2000).

$$
\begin{aligned}
& C_{F e(I I)}=\frac{A_{1} * \varepsilon_{F e(I I)} * l * \alpha-A_{2} * \varepsilon_{F e(I I I)} * l}{\varepsilon_{F e(I I)} * l * \alpha\left(\varepsilon_{F e(I I)} * l-\varepsilon_{F e(I I I)} * l\right)} ; C_{F e(I I I)} \\
& =\frac{A_{2}-A_{1} * \alpha}{\alpha *\left(\varepsilon_{F e(I I)} * l-\varepsilon_{F e(I I I)} * l\right)}
\end{aligned}
$$

Here, $\mathrm{C}_{\mathrm{Fe} \text { (II) }}$ and $\mathrm{C}_{\mathrm{Fe}(\mathrm{III})}$ are the calculated values of $\mathrm{Fe}(\mathrm{II})$ and $\mathrm{Fe}(\mathrm{III})$ concentrations; $\varepsilon_{\mathrm{Fe}(I I)}$ and $\varepsilon_{\mathrm{Fe}(I I I)}$ are the molar absorption coefficients for $\mathrm{Fe}(\mathrm{II})$ and $\mathrm{Fe}(\mathrm{III})$ respectively; 1 is the optical path length; $\alpha$ is the dilution factor; and $A_{1}$ and $A_{2}$ represent the absorption values before and after adding the reducing agent, respectively.

The values of $\varepsilon_{F e(I I)} * l$ and $\varepsilon_{F e(I I I)} * l$ were obtained from the standard curves of $\mathrm{Fe}(\mathrm{II})$ and $\mathrm{Fe}(\mathrm{III})$, respectively. The dilution factor of 0.23 was introduced considering the addition of hydroxylamine hydrochloride (HA) as a reducing agent in the solutions.

For measuring $A_{1}, 1 \mathrm{ml}$ aliquot was withdrawn periodically from each test solution and $100 \mu \mathrm{l}$ of ammonium acetate buffer and $120 \mu \mathrm{l}$ of $4.9 \mathrm{mM}$ ferrozine solution were added to it. The absorbance was measured immediately at $562 \mathrm{~nm}$ wavelength using Shimadzu $1700 \mathrm{UV}-\mathrm{V}$ is spectrophotometer. For measuring $\mathrm{A}_{2}$, the method was similar to the one for measuring $\mathrm{A}_{1}$ except for that $1.5 \mathrm{ml}$ of $3 \mathrm{ml}$ hydroxylamine hydrochloride was added to each $0.5 \mathrm{ml}$ aliquots and left the solution in dark for $15 \mathrm{~min}$ before adding the buffer and ferrozine solution. The sample aliquots were withdrawn using a $10-\mathrm{ml}$ syringe with 0.45 $\mu \mathrm{M}$ PTFE filter to avoid the interference with undissolved hematite particles.

\section{Results and discussions}

The dissolution of iron from minerals has been a subject of intense study because of its significant role as a micronutrient in marine ecosystem (Zinder et al. 1986; Wieland et al. 1988; Stumm and Wollast 1990). Dissolution of iron could be non-reductive, producing $\mathrm{Fe}(\mathrm{III})$, or reductive, producing $\mathrm{Fe}(\mathrm{II})$. In either case, the dissolution follows two major pathways, proton promoted or ligand promoted. The proton promoted dissolution from the Fe minerals results in producing dissolved Fe(III), whereas the ligand-assisted dissolution generates both $\mathrm{Fe}$ (II) and $\mathrm{Fe}$ (III); for instance, if the complex is exposed to UV light, the ligand can act as an electron donor to the Fe(III) metal center to produce photoreductive $\mathrm{Fe}(\mathrm{II})$. The detachment of the $\mathrm{Fe}$ metal center from minerals is the rate limiting step and is promoted by the surrounding ligands and/or protons in the solution (Siffert and Sulzberger 1991). In general, transition metal complexes absorb spectrum significantly in the UV region; however, the photochemistry of $\mathrm{Fe}$ in the ambient environment requires special emphasis because some of the Fe(III) complexes can also absorb radiation in the near UV to some portion of visible spectrum which overlaps with the incoming solar radiation (Graedel et al. 1985).

Figure 1 shows the photoreductive dissolution of $\mathrm{Fe}(\mathrm{II})$ from hematite at four different oxalate concentrations. The 
Fig. 1 The effect of varying oxalate concentration on the photoreductive dissolution of $\mathrm{Fe}(\mathrm{II})$ from hematite. The inset shows the details for the first $5 \mathrm{~h}$. The error bars are representing the range of the triplicate experiments

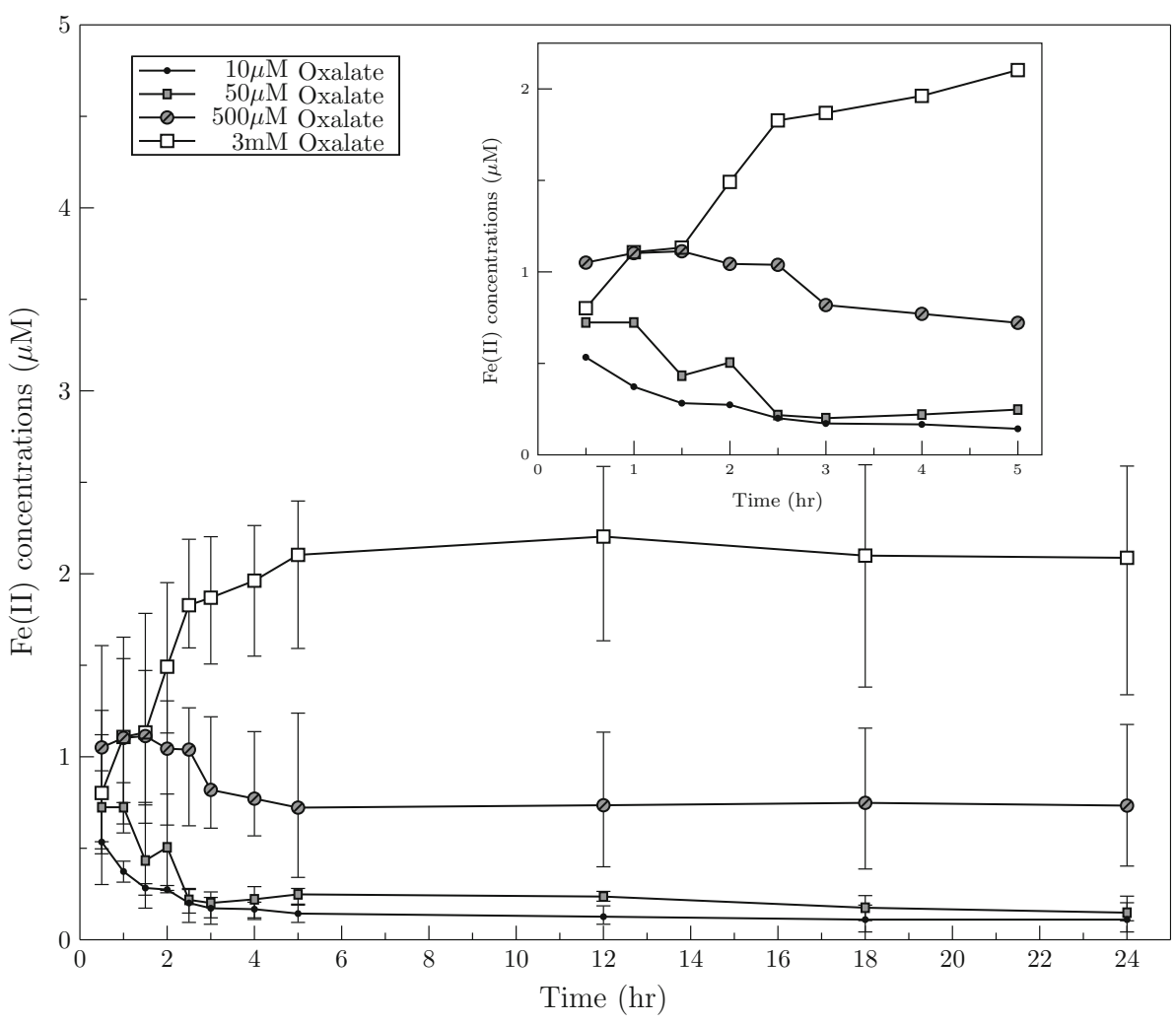

experiment had been conducted under $254 \mathrm{~nm}$ UV light source. The formation of Fe(II) occurred only at sufficiently high concentration of oxalate $(3 \mathrm{mM})$. At lower concentrations of 10 and $50 \mu \mathrm{M}$, the $\mathrm{Fe}(\mathrm{II})$ concentration started to decrease within $1.5 \mathrm{~h}$ of irradiation after a short period of increasing trend, while at the $500 \mu \mathrm{M}$ concentration range, the decreasing trend of $\mathrm{Fe}(\mathrm{II})$ started after $4 \mathrm{~h}$ of irradiation. At high concentration $(3 \mathrm{mM})$, the Pearson correlation coefficient is 0.9 , which demonstrates the consistency among the replicates and fairly stable surface interaction of oxalate with hematite. However, for the lower concentration ranges, the complex nature of the interactions renders them less consistent which is reflected in Tables 1 and 2. These results indicate that the photoreductive dissolution of $\mathrm{Fe}$ (II) from hematite is a function of oxalate concentrations, and the efficiency of $\mathrm{Fe}(\mathrm{II})$ production through this process could vary significantly in the global atmosphere, depending on the loading of this organic ligand in the ambient air.

The variation of $\mathrm{Fe}$ (II) formation under different concentrations of three ligands (oxalate, acetate, and formate) in the presence of $254 \mathrm{~nm}$ UV light was shown in Fig. 2. The Fe(II) production through organic ligand-induced photoreduction varied with changing concentrations for all ligands. However, the more pronounced effect was associated with the concentration variation of oxalate from lower concentrations $(10,50,500 \mu \mathrm{M})$ to a higher $(3 \mathrm{mM})$ concentration. At lower concentrations of oxalate (10 and $50 \mu \mathrm{M})$, the $\mathrm{Fe}(\mathrm{II})$ concentrations showed a sustained substantial decreasing trend after $1 \mathrm{~h}$ of irradiation. Similar patterns were observed at a higher concentration $(500 \mu \mathrm{M})$ starting after $5 \mathrm{~h}$ of irradiation. The concentration of $\mathrm{Fe}$ (II) did not exhibit any increasing trend at any later point in the complete $24 \mathrm{~h}$ of irradiation period. However, under the high oxalate concentration $(3 \mathrm{mM})$, the $\mathrm{Fe}(\mathrm{II})$ concentrations showed a steady increasing trend until it reached the equilibrium ( $\sim$ after $5 \mathrm{~h}$ of irradiation). In the presence of formate and acetate, the $\mathrm{Fe}(\mathrm{II})$ concentrations increased for the initial $5 \mathrm{~h}$ (while a comparatively steeper increasing trend occurred in the first $2 \mathrm{~h}$ ) of irradiation until they attained the equilibrium.

Figure 3 presents a comparative analysis with different organic ligands (oxalate, formate, and acetate) in varying concentrations $(50 \mu \mathrm{M}$ and $3 \mathrm{mM})$, where the organic ligand and hematite mixtures had been irradiated for $24 \mathrm{~h}$ under the UV light, without prior pre-coating. The varying concentration effect of oxalate is even more evident in Fig. 3 than in Fig. 2. For instance, in Fig. 3, at $3 \mathrm{mM}$ oxalate concentration, the soluble $\mathrm{Fe}(\mathrm{II})$ concentration was $\sim 7.5 \mu \mathrm{M}$ at the equilibrium, whereas in the presence of $50 \mu \mathrm{M}$ oxalate concentration, the soluble $\mathrm{Fe}(\mathrm{II})$ concentration was $\sim 2.16 \mu \mathrm{M}$. This indicates an almost $70 \%$ decrease in the photoreductive yield of $\mathrm{Fe}(\mathrm{II})$ when the oxalate concentration varies from $3 \mathrm{mM}$ to $50 \mu \mathrm{M}$. 
Fig. 2 Photoreductive dissolution of $\mathrm{Fe}(\mathrm{II})$ from hematite in the presence of varying concentrations $(10,50$, $500 \mu \mathrm{M}$, and $3 \mathrm{mM}$ ) of oxalate, acetate, and formate. The error bars are representing the range of the triplicate experiments

Fig. 3 The effect of instantaneous UV irradiation on the photoreductive dissolution of $\mathrm{Fe}(\mathrm{II})$ from hematite in the presence of $50 \mu \mathrm{M}$ and $3 \mathrm{mM}$ concentrations of oxalate, acetate, and formate. The error bars are representing the range of the triplicate experiments
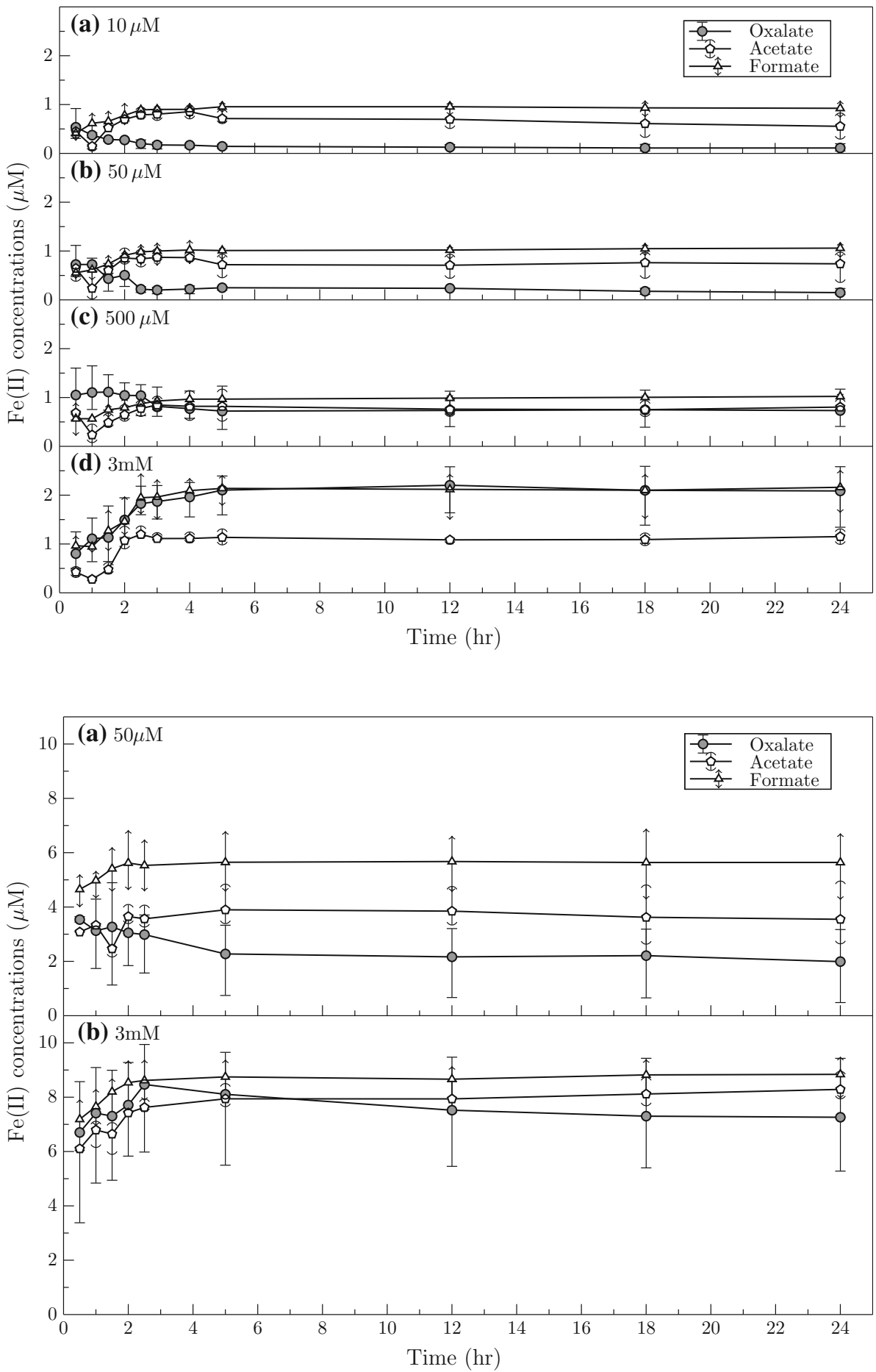

The comparison of the adsorption dissolution of Fe(III) from hematite mineral in the presence of oxalate, formate, acetate, and fluoride at two concentrations $(50 \mu \mathrm{M}$ and $3 \mathrm{mM}$ ) is shown in Fig. 4. The ligand-induced dissolution of $\mathrm{Fe}$ (III) from hematite by oxalate is substantially higher than those by formate and acetate in both concentration ranges. These three ligands were more effective in $\mathrm{Fe}(\mathrm{III})$ dissolution than fluoride; however, in the presence of fluoride, the dissolution of $\mathrm{Fe}(\mathrm{III})$ reached the equilibrium within $2 \mathrm{~h}$.

\section{Effect of varying concentrations and ligands}

Being a d-block element, Fe shows high affinity for complex formation. The half-filled d-orbital in the $\mathrm{Fe}$ (III) ions creates a favorable condition for formation of a mononuclear mono- 
Fig. 4 The adsorption dissolution of $\mathrm{Fe}$ (III) from hematite in the presence of $50 \mu \mathrm{M}$ and $3 \mathrm{mM}$ concentrations of oxalate, acetate, formate, and fluoride. The error bars are representing the range of the repeated set of experiments

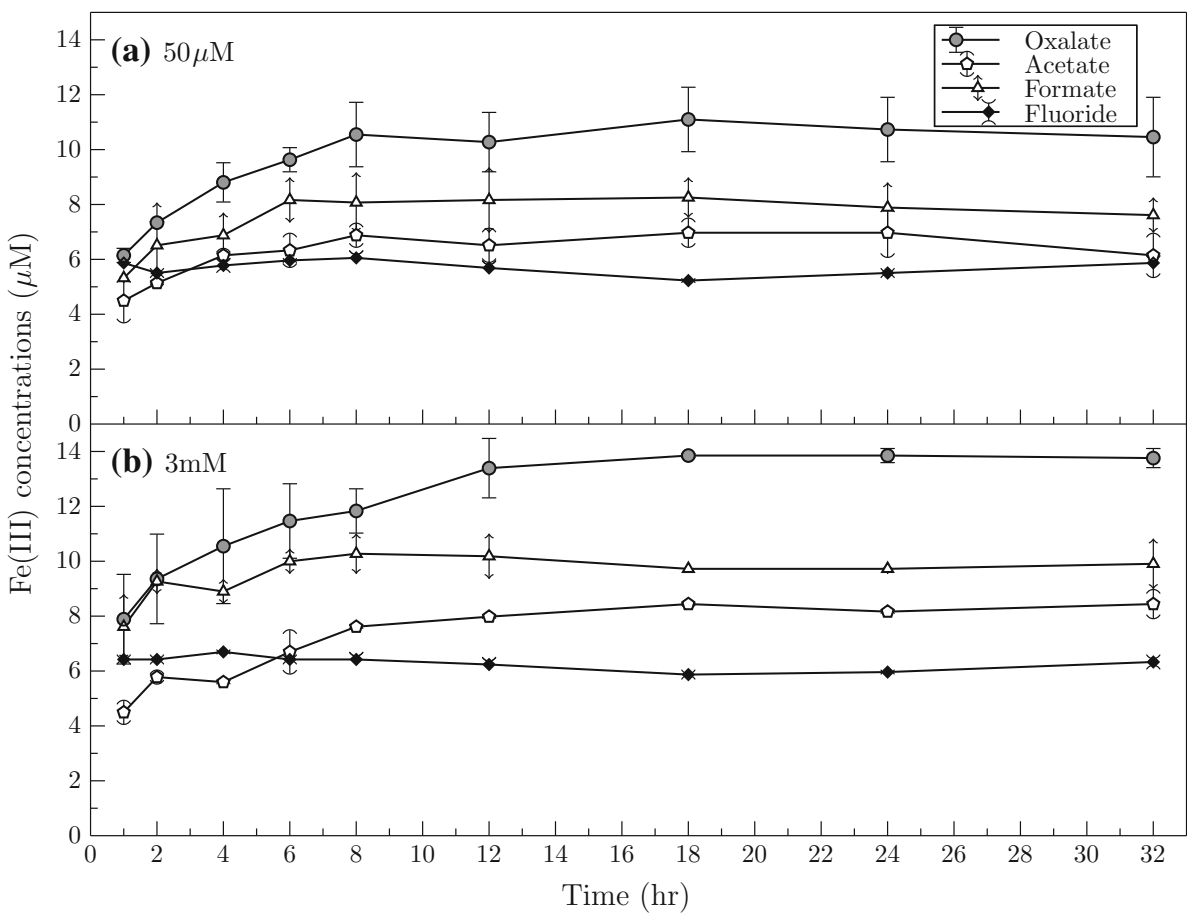

dentate or bi-dentate complex with suitable ligands. The ligands in solution bind with the surface molecules and consequently weaken the bonds closer to the surface metal atom, and this process enhances the liberation of metal $\mathrm{Fe}(\mathrm{III})$ in the solution. When exposed to solar radiation, the $\mathrm{Fe}(\mathrm{III})$-organic ligand complex absorbs the energy from the solar radiation and enters into an excited state. At this stage, the electron donors, such as oxalate, acetate, and formate, act as a bridge and supply electron to the Fe(III) metal center, producing $\mathrm{Fe}(\mathrm{II})$ (Banwart et al. 1989; Sulzberger et al. 1989; Siffert and Sulzberger 1991; Paris et al. 2011). In contrast with acetate and formate, the formation of a bidentate complex with oxalate is thermodynamically more favorable (because the process reduces the net entropy) and has greater stability, and oxalate could be considered as a stronger ligand than acetate and formate. However, under adequate $\mathrm{O}_{2}$ exposure, via reaction mechanisms (2-6), the oxalate radical generates $\mathrm{H}_{2} \mathrm{O}_{2}$ in the medium during the following reactions (Zuo and Hoigne 1992; Siefert et al. 1994).

$$
\begin{aligned}
& >\mathrm{Fe}^{\mathrm{III}} \mathrm{C}_{2} \mathrm{O}_{4}^{-} \stackrel{h \delta}{\rightarrow}>\mathrm{Fe}^{\mathrm{II}} \mathrm{C}_{2} \mathrm{O}_{4}^{-} \\
& >\mathrm{Fe}^{\mathrm{II}} \mathrm{C}_{2} \mathrm{O}_{4}^{-} \leftrightarrow>\mathrm{Fe}^{\mathrm{II}}+\mathrm{CO}_{2}+\mathrm{CO}_{2}^{-} \\
& {\left[\mathrm{Fe}^{\mathrm{III}}\left(\mathrm{C}_{2} \mathrm{O}_{4}^{-2}\right)_{n}\right]^{(3-2 n)} \stackrel{h \delta}{\leftrightarrow} \mathrm{Fe}^{\mathrm{II}}+(n-1) \mathrm{C}_{2} \mathrm{O}_{4}^{-}+\mathrm{C}_{2} \mathrm{O}_{4}^{-}} \\
& \mathrm{C}_{2} \mathrm{O}_{4}^{-}+\mathrm{O}_{2} \stackrel{H^{+}}{\rightarrow} \frac{\mathrm{HO}_{2}}{\mathrm{O}_{2}^{-}}+2 \mathrm{CO}_{2}
\end{aligned}
$$

$\frac{\mathrm{HO}_{2}}{\mathrm{O}_{2}^{-}}+\mathrm{Fe}^{\mathrm{II}} \stackrel{H^{+}}{\rightarrow} \mathrm{H}_{2} \mathrm{O}_{2}+\mathrm{Fe}^{\mathrm{III}}$

A previous study shows that oxalate is sensitive to photolysis at approximately $320 \mathrm{~nm}$ wavelength and forms peroxide radicals (Zuo and Hoigne 1992). Even though our experiment has been conducted at $254 \mathrm{~nm}$ wavelength of UV light, the formation of $\mathrm{H}_{2} \mathrm{O}_{2}$ in the medium, either via interaction of oxalate with surrounding $\mathrm{O}_{2}$ or by photolysis of oxalate, could lead to increased re-oxidation of Fe(II) to $\mathrm{Fe}(\mathrm{III})$ and decreases the efficiency of oxalate in producing $\mathrm{Fe}$ (II) from hematite. On the other hand, under similar conditions, acetate and formate have not been reported to produce $\mathrm{H}_{2} \mathrm{O}_{2}$; therefore, these two ligands should remain effective in photoreduction of hematite. In this study, the production of $\mathrm{Fe}$ (II) via photoreduction in the presence of the three organic ligands was generally fast, occurring within a few minutes of exposure to UV light. However, at low oxalate concentrations, the $\mathrm{Fe}$ (II) concentrations exhibited a sharp decreasing trend with time (Figs. 1, 2, 3 ), suggesting that the formation of $\mathrm{H}_{2} \mathrm{O}_{2}$ must have influenced the $\mathrm{Fe}(\mathrm{II})$ production rate. It is noteworthy that in Fig. 3, a slight decrease in dissolved Fe(II) concentration is observed after $6 \mathrm{~h}$ in the presence of oxalate. The labile $\mathrm{Fe}$ (III)-oxalate bonding could facilitate $\mathrm{Fe}$ (III) dissolution, which might suppress the $\mathrm{Fe}$ (III) to $\mathrm{Fe}(\mathrm{II})$ reduction. Another plausible explanation could be the oxidation of $\mathrm{Fe}$ (II) to $\mathrm{Fe}$ (III) in the oxalate system in the presence of oxygen. Since the decrease in $\mathrm{Fe}(\mathrm{II})$ concentrations after $6 \mathrm{~h}$ is low compared to its previous values, it would be very 
ambiguous to explain the possible reasons with definite claim. The varying concentrations of acetate and formate were not observed to exhibit significant effect on $\mathrm{Fe}$ dissolution; therefore, the dissolved Fe(II) concentrations were fairly constant after $\sim 3 \mathrm{~h}$ of irradiation.

When the oxalate concentration is high, the ligand effect of oxalate should predominate the re-oxidization of $\mathrm{Fe}$ (III) to $\mathrm{Fe}(\mathrm{II})$ via in situ production of $\mathrm{H}_{2} \mathrm{O}_{2}$ in deciding the fate of $\mathrm{Fe}(\mathrm{II})$ production. The data analyses with the Visual Minteq 3.1 model show that at a higher oxalate concentration $(3 \mathrm{mM})$, the dominant $\mathrm{Fe}$-oxalate complex is $\mathrm{Fe}$ (oxalate) $3_{3}^{-3}$ (Table 3 ) which indicates the stronger ligand effect at higher concentrations. The high oxalate concentration results in increasing probability of chaos and consequently higher entropy in the system; however, binding with hematite and forming the complex should decrease the entropy (assuming the changes in enthalpy due to $\mathrm{Fe}$ (III)oxalate complexation at higher oxalate concentration would be in order similar to oxalate at lower concentrations), thereby favoring the ligand effect of oxalate at higher concentrations.

However, when the concentrations of oxalate are in lower ranges, i.e., $10-500 \mu \mathrm{M}$, the net change in the entropy due to complex formation with hematite does not favor the process enough to overcome the oxidizing effect of $\mathrm{H}_{2} \mathrm{O}_{2}$ energetically. This behavior is exhibited in Fig. 1; to wit, oxalate is significantly less efficient than acetate and formate in low concentrations, mostly in remote marine locations, but significantly more efficient than acetate, and almost as efficient as formate in high concentrations (Figs. 2, 3), especially in urban regions. A study by Zhu et al (1993) shows that the soluble $\mathrm{Fe}(\mathrm{II})$ concentration increases significantly when an acidified $87 \mu \mathrm{M}$ of $\mathrm{Fe}$ (III) solution is irradiated in the presence of $0.1 \mathrm{M} \mathrm{Na}_{2} \mathrm{C}_{2} \mathrm{O}_{4}$ solution, whereas the soluble $\mathrm{Fe}(\mathrm{II})$ concentration decreases to almost below detection limit when the mixture is brought back to dark. In connection with our experiment, this study suggests a stronger photoreductive capacity of oxalate when it is present at sufficiently higher concentration level in the solution and the oxidizing effect of $\mathrm{H}_{2} \mathrm{O}_{2}$ predominates immediately after irradiation shuts off. In this experiment, however, even at constant irradiation, the $\mathrm{Fe}$ (II) concentration starts to decrease after $\sim 4 \mathrm{~h}$ of irradiation in the presence of $500 \mu \mathrm{M}$ oxalate concentration and after $\sim 1.5 \mathrm{~h}$ in the presence of 10 and $50 \mu \mathrm{M}$ oxalate solution. It is interestingly to note that no distinct effect of varying concentrations has been observed in the case of acetate and formate. Similar trend showing the fastest photoreduction was observed when formate was used as the electron donor and hematite as the acceptor where the rate of photoreduced $\mathrm{Fe}(\mathrm{II})$ formation was $2 \mathrm{nM} /$ min with formate and $0.5 \mathrm{nM} / \mathrm{min}$ in the presence of acetate (the rate of $\mathrm{Fe}$ (II) production in the presence of oxalate was not provided) (Pehkonen et al. 1993). High efficiency of formate may be attributed to its comparatively smaller size and consequently reduced possibility of steric hindrance. Formate has been observed to be the most effective among these three ligands for photoreduction of Fe minerals (Zuo and Hoigne 1992). For example, a study conducted to investigate the fog and cloud water samples at Los Angeles, California, reported that oxalate has not been observed to have an effect on $\mathrm{Fe}(\mathrm{II})$ dissolution in nature, unlike formate and acetate that showed high correlations with $\mathrm{Fe}(\mathrm{II})$ concentrations, whereas oxalate concentrations were found to be highly positively correlated with the $\mathrm{H}_{2} \mathrm{O}_{2}$ concentrations (Erel et al. 1993).

\section{Adsorption dissolution of hematite in presences of oxalate, acetate, formate, and fluoride}

Although the previous photoreductive dissolution experiment suggested that formate should be considered a stronger ligand for inducing $\mathrm{Fe}$ dissolution from hematite at lower concentrations, Fig. 4 clearly demonstrates the dominance of oxalate over formate and acetate in forming $\mathrm{Fe}(\mathrm{III})$ via adsorption in both high and low concentrations. It is evident that the effect of varying concentrations is not significant with acetate and formate. However, the Fe(III)
Table 3 Speciation of $\mathrm{Fe}-$ ligand complexes at varying ligand concentrations (Visual Minteq 3.1 Chemical model)

\begin{tabular}{|c|c|c|c|c|}
\hline Speciation & $10 \mu \mathrm{M}$ & $50 \mu \mathrm{M}$ & $500 \mu \mathrm{M}$ & $3 \mathrm{mM}$ \\
\hline$\left[\mathrm{Fe}-(\text { Oxalate })_{2}\right]^{-}$ & $6.77 \mathrm{E}-09$ & $1.6 \mathrm{E}-07$ & $8.98 \mathrm{E}-06$ & $5.17 \mathrm{E}-05$ \\
\hline$\left[\mathrm{Fe}-(\mathrm{Oxalate})_{2}\right]^{-2}$ & $9.45 \mathrm{E}-22$ & $1.98 \mathrm{E}-20$ & $6.1 \mathrm{E}-19$ & $2.20 \mathrm{E}-18$ \\
\hline$\left[\mathrm{Fe}-(\mathrm{Oxalate})_{3}\right]^{-3}$ & $5.69 \mathrm{E}-10$ & $7.15 \mathrm{E}-08$ & $3.39 \mathrm{E}-05$ & $6.39 \mathrm{E}-04$ \\
\hline [Fe-Oxalate] (aq.) & $3.17 \mathrm{E}-18$ & $1.31 \mathrm{E}-17$ & $5.09 \mathrm{E}-17$ & $6.62 \mathrm{E}-17$ \\
\hline$[\mathrm{Fe}-\mathrm{Oxalate}]^{+}$ & $9.68 \mathrm{E}-10$ & $4.73 \mathrm{E}-09$ & $3.57 \mathrm{E}-08$ & $8.77 \mathrm{E}-08$ \\
\hline$[\mathrm{Fe} \text {-Formate }]^{+2}$ & $2.10 \mathrm{E}-15$ & $1.05 \mathrm{E}-14$ & $1.08 \mathrm{E}-13$ & $6.91 \mathrm{E}-13$ \\
\hline$\left[\mathrm{Fe}-(\text { Acetate })_{2}\right]^{+}$ & $1.62 \mathrm{E}-17$ & $4.05 \mathrm{E}-16$ & $4.06 \mathrm{E}-14$ & $1.47 \mathrm{E}-12$ \\
\hline$\left[\mathrm{Fe}-(\text { Acetate })_{3}\right]$ (aq.) & $2.48 \mathrm{E}-21$ & $3.10 \mathrm{E}-19$ & $3.10 \mathrm{E}-16$ & $6.67 \mathrm{E}-14$ \\
\hline$[\mathrm{Fe}-\text { Acetate }]^{+}$ & $3.64 \mathrm{E}-21$ & $1.82 \mathrm{E}-20$ & $1.80 \mathrm{E}-19$ & $1.05 \mathrm{E}-18$ \\
\hline$[\mathrm{Fe}-\text { Acetate }]^{+2}$ & $5.22 \mathrm{E}-15$ & $2.61 \mathrm{E}-14$ & $2.64 \mathrm{E}-13$ & $1.63 \mathrm{E}-12$ \\
\hline
\end{tabular}


dissolution rate increased dramatically in the presence of increased oxalate concentrations. The reason could be attributed to the fact that oxalate can form both outersphere and inner-sphere complexes and thereby resulting in increased dissolution of Fe(III) from hematite (Sulzberger et al. 1989).

A comparative analysis of fluoride from this study with the organic ligands (acetate, formate, and oxalate) shows that the fluoride has no significant effect on adsorption dissolution of hematite to form Fe(III). With the fluoride concentrations at $50 \mu \mathrm{M}$ and $3 \mathrm{mM}$, the average dissolved $\mathrm{Fe}(\mathrm{III})$ concentrations after $1 \mathrm{~h}$ were 5.5 and $6.4 \mu \mathrm{M}$, respectively, which remain almost unchanged throughout the experiment, which is evident from Table 2. This phenomenon strongly suggests that the organic ligand-induced dissolution is highly effective in dissolved Fe(III) formation in comparison with inorganic ligand, such as fluoride, and this could be attributed to the stronger capacity of complex formation of the organic ligands with Fe minerals.

\section{Comparison between instantaneous irradiation on Fe(III)-ligand complex}

Figure 4 shows that $10-12 \mu \mathrm{M} \quad \mathrm{Fe}(\mathrm{III})$ was dissolved through adsorption-dissolution from hematite in the presence of the organic ligands used in this study. On the other hand, the comparative analysis between Figs. 2 and 3 indicates that substantially low amount of $\mathrm{Fe}(\mathrm{II})(\sim 2 \mu \mathrm{M})$ was released through photoreduction from hematite when the mixtures were irradiated after the Fe(III)-ligand complex attained the equilibrium, but if the mixtures were allowed to be irradiated after immediate $\mathrm{Fe}$ (III)-ligand complex formation, as evident in Fig. 3, the production of $\mathrm{Fe}(\mathrm{II})$ was significantly higher $(\sim 10 \mu \mathrm{M})$ and comparable to the $\mathrm{Fe}(\mathrm{III})$ production via adsorption-dissolution (Fig. 4). Similar trends had been documented in other studies (Rijkenberg et al. 2006), where Fe(III)-ligand complexes were unable to produce Fe(II) after UV irradiation, and it was hypothesized that a different colloidal form of $\mathrm{Fe}$ was responsible for photoreductive production of $\mathrm{Fe}$ (II) rather than $\mathrm{Fe}(\mathrm{III})$-organic complexes. In contrast, the results of our experiment, as demonstrated in Fig. 3, however, clearly indicate that $\mathrm{Fe}$ (III)-organic ligand complexes can photoreductively produce $\mathrm{Fe}$ (II) via instantaneous surface complexation with organic ligands. In order for the photoreduction to happen, the ligand has to supply the electron to the Fe(III) metal center in a higher excited energy state, which requires sufficient supply of energy from UV light source. Based on these results, we hypothesize that the photoreduction process is fast and the subsequent ligand to metal electron transfer should occur soon after the ligand-metal bond was formed. Once the ligand-Fe(III) complex reaches the equilibrium in the solution, it becomes stable and thereby difficult to induce the photoreduction. This mechanism could be relevant for estimating the amount of dissolved $\mathrm{Fe}(\mathrm{II})$ from $\mathrm{Fe}(\mathrm{III})$ ligand complexes via photoreduction.

The results from these laboratory experiments further infer that the photoreduction of $\mathrm{Fe}(\mathrm{III})$-ligand complexes and the consequent formation of $\mathrm{Fe}(\mathrm{II})$ are relevant when (1) persistent solar radiation is available for a long period of time to stimulate the Fe(III)-ligand complexes to a higher energy state so that the electron transfer process can take place and (2) organic ligands in the aerosols would come in contact with freshly eroded Fe minerals in the air.

\section{Comparison with observational data}

The results from this study are in good agreement with the data collected during field operations (Chen and Siefert 2004; Buck et al. 2010; Xia and Gao 2011; Gao et al. 2013; $\mathrm{Xu}$ and Gao 2014). Results from this study suggested that the mass ratio of oxalate concentration to the total $\mathrm{Fe}$ concentration should be at least 1 in order to attain the steady state production of photoreduced Fe(II). A study carried out by Xia and Gao (2011) at Newark in NJ, an urban location, where the average oxalate concentration was $\sim 4$ times higher than the average concentration of the total $\mathrm{Fe}$, shows that the oxalate concentration was highly correlated with the dissolved Fe(II) concentration (correlation coefficient $=0.90)$, whereas, in a remote Antarctic region, where the same ratio of oxalate to the total $\mathrm{Fe}$ was 0.16 , the correlation between soluble $\mathrm{Fe}(\mathrm{II})$ and oxalate concentrations was significantly low (correlation coefficient $=0.03)($ Gao et al. 2013; Xu and Gao 2014). Similar pattern was observed over the North Atlantic (Chen and Siefert 2004), where the concentration ratio of oxalate to the total Fe was above 1, and the correlation coefficient between $\mathrm{Fe}$ (II) with oxalate was 0.35 . A comparison of relevant data from different studies is shown in Fig. 5 (Chen and Siefert 2004; Buck et al. 2010; Xia and Gao 2011; Gao et al. 2013; $\mathrm{Xu}$ and Gao 2014). The $\mathrm{X}$-axis represents the ratio $(\mathrm{R})$ of the oxalate concentrations to the total $\mathrm{Fe}$ concentrations and the $\mathrm{y}$-axis represents the correlation coefficient between soluble $\mathrm{Fe}$ (II) with the oxalate with all data points where the ratios of oxalate to the total Fe were greater than $\mathrm{R}$ and at least 5 data points are available. In this comparison, the data set from Buck et al. (2010) was divided into two groups: the tropical region where the data values were from south of $23.5^{\circ} \mathrm{N}$ and the temperate region where the values were from north of $23.5^{\circ} \mathrm{N}$. Figure 5 reveals that all the data sets are associated with a sharp increase (except for Antarctica) where the correlation coefficients in the y-axis show a sudden elevation (represented by the solid vertical lines). Based on the results from these observations and from this laboratory 
Fig. 5 Empirical correlation between oxalate and soluble $\mathrm{Fe}$ (II) concentrations when the ratio between oxalate and total $\mathrm{Fe}$ is at least $\mathrm{R}$, plotted against the parameter $\mathrm{R}$. The data are collected from Buck et al. (2010), Chen and Siefert (2004), Gao et al. (2013), Xia and Gao (2008, 2011), Xu and Gao (2014)

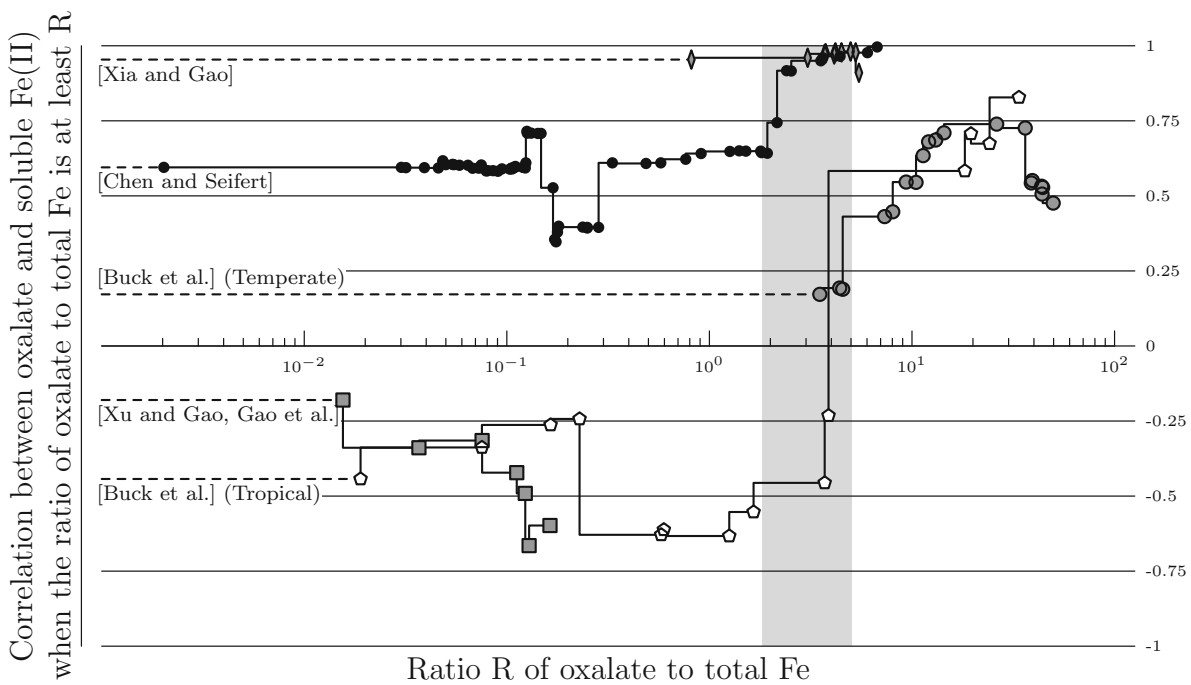

experiment, it appears that the values of $\mathrm{R}$ have to be at least 1-6.5 in order for oxalate to influence the photoreduction process. When the $\mathrm{R}$ value is low (below 1), oxalate could be inefficient for producing soluble Fe(II) via photoreduction, and other organic ligands such as formate may play more important role in $\mathrm{Fe}$ dissolution. On the other hand, when the $\mathrm{R}$ value is high (above 1.0), oxalate could be highly effective for photoreductive production of soluble $\mathrm{Fe}(\mathrm{II})$.

\section{Conclusion}

Results from this study lead to following conclusions:

1. Among the three ligands tested in this study, oxalate is the strongest organic ligand to induce adsorption dissolution of hematite to produce dissolved Fe(III).

2. In oxic environment and under UV radiation, the varying concentrations of oxalate play a crucial role in determining the $\mathrm{Fe}$ speciation: The production of $\mathrm{Fe}(\mathrm{II})$ via photoreduction of $\mathrm{Fe}$ (III) could be substantially hindered at low concentrations, and the concentration ratios of oxalate to the total $\mathrm{Fe}$ should be at least 1:1 or higher. However, formate and acetate were not sensitive with the concentration variation during the photoreduction of hematite.

3. Prior coating with organic ligands significantly could reduce the photoreduction of hematite. For instance, in the presence of $3 \mathrm{mM}$ ligand concentration, the amount of soluble $\mathrm{Fe}(\mathrm{II})$ decreased $\sim 70-80 \%$ when the $\mathrm{Fe}(\mathrm{III})$-ligand complexes were irradiated after equilibrium as compared with instantaneous irradiation on the in situ produced nascent $\mathrm{Fe}(\mathrm{III})$-ligand complexes.
The $\mathrm{Fe}$ deposited from the atmosphere readily gets complexed with organic ligands in sea waters in the surface ocean, and the complexation with organic ligands substantially hinders the photoreduction of hematite. These processes also depend on the mineralogy of the Fe minerals, sources, and abundance of the ligands, and thus more field experiments need to be carried out for better understanding of Fe dissolutions in dust in addition to the laboratory-based experiments.

Acknowledgments This research was sponsored by the US National Science Foundation Award 1435871 and was carried out at Rutgers University, Newark Campus. We would like to thank Dr. John Reinfelder and Dr. Ashaki Rouff for helpful discussions. We also thank two anonymous reviewers for constructive comments that significantly improved this manuscript.

\section{References}

Banwart S, Simon D, Stumm W (1989) The role of oxalate in accelerating the reductive dissolution of hematite $\left(-\mathrm{Fe}_{2} \mathrm{O}_{3}\right)$ by ascorbate. Colloids Surf 39(2):303-309

Buck CS et al (2010) The solubility and deposition of aerosol Fe and other trace elements in the North Atlantic Ocean: observations from the A16 N CLIVAR/CO 2 repeat hydrography section. Mar Chem 120(1):57-70

Chebbi A, Carlier P (1996) Carboxylic acids in the troposphere, occurrence, sources, and sinks: a review. Atmos Environ 30(24):4233-4249

Chen H, Grassian VH (2013) Iron dissolution of dust source materials during simulated acidic processing: the effect of sulfuric, acetic, and oxalic acids. Environ Sci Technol 47(18):10312-10321

Chen Y, Siefert RL (2004) Seasonal and spatial distributions and dry deposition fluxes of atmospheric total and labile iron over the tropical and subtropical North Atlantic Ocean. J Geophys Res: Atmos 109(D9)

Dey S, Goswami S, Ghosh UC (2004) Hydrous ferric oxide (HFO)—a scavenger for fluoride from contaminated water. Water Air Soil Pollut 158(1):311-323 
Dodgen HW, Rollefson GK (1949) The complex ions formed by iron and thorium with fluoride in acid solution. J Am Chem Soc 71(8):2600-2607

Erel Y, Pehkonen SO, Hoffmann MR (1993) Redox chemistry of iron in fog and stratus clouds. J Geophys Res: Atmos (1984-2012) 98(D10):18423-18434

Finden DAS, Tipping E, Jaworski GHM, Reynolds CS (1984) Lightinduced reduction of natural iron (III) oxide and its relevance to phytoplankton. Nature 309:783-784

Gao Y, Xu G, Zhan J, Zhang J, Li W, Lin Q, Chen L, Lin H (2013) Spatial and particle-size distributions of atmospheric dissolved iron in Aerosols and its input to the Southern Ocean and Coastal East Antarctica. J Geophys Res: Atmos 118:1-15. doi:10.1002/ 2013JD020367

Gledhill M, van den Berg CMG (1995) Measurement of the redox speciation of iron in seawater by catalytic cathodic stripping voltammetry. Mar Chem 50(1):51-61

Graedel TE, Weschler CJ, Mandich ML (1985) Influence of transition metal complexes on atmospheric droplet acidity. Nature 317:240-242

Jickells TD, An ZS, Andersen KK, Baker AR, Bergametti G, Brooks N, Torres R (2005) Global iron connections between desert dust, ocean biogeochemistry, and climate. Science 308(5718):67-71

Johansen AM, Siefert RL, Hoffmann MR (2000) Chemical composition of aerosols collected over the tropical North Atlantic Ocean. J Geophys Res: Atmos (1984-2012) 105(D12):15277-15312

Johnson KS, Gordon RM, Coale KH (1997) What controls dissolved iron concentrations in the world ocean? Mar Chem 57(3):137-161

Kawamura K, Kaplan IR (1983) Organic compounds in the rainwater of Los Angeles. Environ Sci Technol 17(8):497-501

Kawamura K, Kaplan IR (1987) Motor exhaust emissions as a primary source for dicarboxylic acids in Los Angeles ambient air. Environ Sci Technol 21(1):105-110

Kawamura K, Kouichi I (1993a) Seasonal changes in the distribution of dicarboxylic acids in the urban atmosphere. Environ Sci Technol 27(10):2227-2235

Kawamura K, Kouichi U (1993b) Distributions of low molecular weight dicarboxylic acids in the North Pacific aerosol samples. J Oceanogr 49(3):271-283

Kawamura K, Sakaguchi F (1999) Molecular distributions of water soluble dicarboxylic acids in marine aerosols over the Pacific Ocean including tropics. J Geophys Res: Atmos (1984-2012) 104(3):3501-3509

Keiichiro $\mathrm{H}$ et al (2002) Concentration trends and mixing states of particulate oxalate in Arctic boundary layer in winter/spring. J Geophys Res: Atmos (1984-2012) 107(D19):AAC-12

Krieger UK, Corti T, Cziczo DJ et al (2006) Oxalic acid as a heterogeneous ice nucleus in the upper troposphere and its indirect aerosol effect. Atmos Chem Phys 6(10):3115-3129

Li SM, Winchester JW (1993) Water soluble organic constituents in Arctic aerosols and snow pack. Geophys Res Lett 20(1):45-48

Liu X, Millero FJ (2002) The solubility of iron in seawater. Mar Chem 77(1):43-54

Mackie DS, Boyd PW, Hunter KA, McTainsh GH (2005) Simulating the cold processing of iron in Australian dust: $\mathrm{pH}$ and dust concentration. Geophys Res Lett 32:L06809

Martin John $\mathrm{H}$ (1990) Glacial-interglacial $\mathrm{CO}_{2}$ change: the iron hypothesis. Paleoceanogr Phy 5(1):1-13

Martin John H, Fitzwater SE (1988) Iron deficiency limits phytoplankton growth in the north-east pacific subarctic. Nature 331(3414343):947-975

Martin JH, Fitzwater SE, Gordon RM (1990) Iron deficiency limits phytoplankton growth in Antarctic waters. Global Biogeochem Cycles 4(1):5-12
Naito K, Matsui M, Imai I (2005) Ability of marine eukaryotic red tide microalgae to utilize insoluble iron. Harmful Algae 4(6): 1021-1032

Paris R, Desboeufs KV (2013) Effect of atmospheric organic complexation on iron-bearing dust solubility. Atmos Chem Phys 13(9):4895-4905

Paris R, Desboeufs KV, Journet E (2011) Variability of dust iron solubility in atmospheric waters: investigation of the role of oxalate organic complexation. Atmos Environ 45(36):6510-6517

Pehkonen SO, Siefert R, Erel Y, Webb S, Hoffmann MR (1993) Photoreduction of iron oxyhydroxides in the presence of important atmospheric organic compounds. Environ Sci Technol 27(10):2056-2062

Rijkenberg MJ, Gerringa LJ, Velzeboer I, Timmermans KR, Buma AG, de Baar HJ (2006) Iron-binding ligands in Dutch estuaries are not affected by UV induced photochemical degradation. Mar Chem 100(1):11-23

Rue EL, Bruland KW (1995) Complexation of iron (III) by natural organic ligands in the Central North Pacific as determined by a new competitive ligand equilibration/adsorptive cathodic stripping voltammetric method. Mar Chem 50(1):117-138

Shaked Y, Kustka AB, Morel FM (2005) A general kinetic model for iron acquisition by eukaryotic phytoplankton. Limnol Oceanogr 50(3):872-882

Siefert RL et al (1994) Iron photochemistry of aqueous suspensions of ambient aerosol with added organic acids. Geochim Cosmochim Acta 58(15):3271-3279

Siffert C, Sulzberger B (1991) Light-induced dissolution of hematite in the presence of oxalate. A case study. Langmuir 7(8): $1627-1634$

Soli AL, Byrne RH (1996) The hydrolysis and fluoride complexation behavior of $\mathrm{Fe}(\mathrm{III})$ at $25^{\circ} \mathrm{C}$ and 0.68 molal ionic strength. J Solut Chem 25(8):773-785

Stookey LL (1970) Ferrozine-a new spectrophotometric reagent for iron. Anal Chem 42(7):779-781

Stumm W, Wollast R (1990) Coordination chemistry of weathering: kinetics of the surface-controlled dissolution of oxide minerals. Rev Geophys 28(1):53-69

Sulzberger B, Suter D, Siffert C, Banwart S, Stumm W (1989) Dissolution of $\mathrm{Fe}(\mathrm{III})$ (hydr) oxides in natural waters; laboratory assessment on the kinetics controlled by surface coordination. Mar Chem 28(1):127-144

Sunda WG, Huntsman SA (1997) Interrelated influence of iron, light and cell size on marine phytoplankton growth. Nature 390(6658):389-392

Sung W, Morgan JJ (1980) Kinetics and product of ferrous iron oxygenation in aqueous systems. Environ Sci Technol 14(5):561-568

Turekian VC, Macko SA, Kene WC (2003) Concentrations, isotopic compositions, and sources of size-resolved, particulate organic carbon and oxalate in near-surface marine air at Bermuda during spring. J Geophys Res: Atmos 108(D5)

van den Berg CMG (1995) Evidence for organic complexation of iron in seawater. Mar Chem 50(1):139-157

Viollier E, Inglett PW, Hunter K, Roychoudhury AN, Van Cappellen $\mathrm{P}$ (2000) The ferrozine method revisited: $\mathrm{Fe}(\mathrm{II}) / \mathrm{Fe}(\mathrm{III})$ determination in natural waters. Appl Geochem 15:785-790

Voelker BM, Sulzberger B (1996) Effects of fulvic acid on Fe(II) oxidation by hydrogen peroxide. Environ Sci Technol 30(4):1106-1114

Wang Y, Reardon EJ (2001) Activation and regeneration of a soil sorbent for defluoridation of drinking water. Appl Geochem 16(5):531-539 
Wieland E, Wehrli B, Stumm W (1988) The coordination chemistry of weathering: III. A generalization on the dissolution rates of minerals. Geochim Cosmochim Acta 52(8):1969-1981

$\mathrm{Wu} J$ et al (2001) Soluble and colloidal iron in the oligotrophic North Atlantic and North Pacific. Science 293(5531):847-849

Xia L, Gao Y (2010) Chemical composition and size distributions of coastal aerosols observed on the US East Coast. Mar Chem 119(1):77-90

Xia L, Gao Y (2011) Characterization of trace elements in PM 2.5 aerosols in the vicinity of highways in northeast New Jersey in the US east coast. Atmos Pollut Res 2(1):34-44

Xu N, Gao Y (2008) Characterization of hematite dissolution affected by oxalate coating, kinetics and $\mathrm{pH}$. Appl Geochem 23(4):783-793

Xu G, Gao Y (2014) Atmospheric trace elements in aerosols observed over the Southern Ocean and coastal East Antarctica. Polar Res $33: 23973$
Zhu X, Prospero JM, Savoie DL, Millero FJ, Zika RG, Saltzman ES (1993) Photoreduction of iron (III) in marine mineral aerosol solutions. J Geophys Res: Atmos (1984-2012) 98(D5):9039-9046

Zhu XR, Prospero JM, Millero FJ (1997) Diel variability of soluble $\mathrm{Fe}$ (II) and soluble total $\mathrm{Fe}$ in North African dust in the trade winds at Barbados. J Geophys Res: Atmos (1984-2012) 102(D17):21297-21305

Zinder B, Furrer G, Stumm W (1986) The coordination chemistry of weathering: II. Dissolution of Fe(III) oxides. Geochim Cosmochim Acta 50(9):1861-1869

Zuo Y, Hoigne J (1992) Formation of hydrogen peroxide and depletion of oxalic acid in atmospheric water by photolysis of iron (III)-oxalato complexes. Environ Sci Technol 26(5):1014-1022 